[Agr. Biol. Chem., Vol. 25, No. 6, p. 461 465, 1961]

\title{
Transformations of Cardio-active Steroids by Microorganisms.
}

\author{
Part I. Microbial Dehydrogenation of 3-Hydroxyl Group of \\ Digitalis Cardiac Aglycone*
}

By Yoshio Nozaki

Research Laboratory of Shionogi \& Co., Ltd., Amagasaki, Hyôgo

Received January 16, 1961

\begin{abstract}
Microbial dehydrogenations of $3 \boldsymbol{\beta}$-hydroxyl groups of Digitalis cardiac aglycones by Calonectria decora and Nigrospora sphaerica were studied, both of which exhibited similar transformation pattern. Digitoxigenin was transformed exclusively into 3-dehydrodigoxigenin by $C$. decora and into digoxigenin and 3-dehydro-digoxigenin by $N$. sphaerica. Both gitoxigenin and 3-acetyl-gitoxigenin were dehydrogenated to 3-dehydrogitoxigenin. 3-Dehydro-16acetylgitoxigenin was also detected among the bioconversion products of 16-acetylgitoxigenin and 3,16-diacetylgitoxigenin by these two species.
\end{abstract}

Since the successful establishment of the application of microorganisms to the synthesis of biologically active $\mathrm{C}_{19}$ and $\mathrm{C}_{21}$ steroids, interest has also been awaken in the field of microbial metabolism of cardio-active steroids. Microbial attacks hitherto known towards this group of steroid are: hydrolysis of glycoside linkage and of acyl group attached to the hydroxyl present in the steroid nucleus or in the sugar moiety ${ }^{1 \sim 3)}$; introduction of hydroxyl groups at $5 \beta^{4)}, 7 \beta^{5)}, 11 \alpha^{6)}, 12 \beta^{3,7)}$ and $16 \beta^{8)}$ positions of steroid aglycones; and reduction of 3-ketones to the 3-epi-hydroxyl groups ${ }^{2}$.

In this paper are described the microbial

\footnotetext{
* A part of this paper was presented at "Symposium on Chem istry of Digitalis Cardiac Glycosides", the 13th Annual Meeting of the Pharmaceutical Society of Japan, Tokyo, April 4, 1960.

1) A. Stoll, T. Renz and A. Brack, Helv. Chim. Act., 34, 2301 (1951).

2) Ch. Tamm and A. Gubler, Helv. Chim. Acta, 42, 239 (1959)

3) M. Okada, A. Yamada and M. Ishidate, Chem. Pharm. Bull., 8, 530 (1960).

4) H. Ishii, Yakugaku Zasshi, in contribution.

5) H. Ishii, Y. Nozaki, T. Okumura and D. Satoh, ibid., 80, 1150 (1960).

6) E. Titus, Abstracts of Papers, 136th Meeting, Am. Chem. Soc., Atlantic City, New Jersey, September 13 to 18, 1959, p. 14 A.

7) A. Gubler and Ch. Tamm, Helv. Chim. Acta, 41, 297 (1958)

8) H. Nawa, et al., Nature, 184, 469 (1959)
}

dehydrogenations of $3 \beta$-hydroxyl groups of Digitalis cardiac aglycones with or without the concomitant introduction of hydroxyl group at $12 \beta$ position. Concerning the dehydrogenation reactions of 3-hydroxyl groups of steroids by microorganisms, pregnenolone ${ }^{9)}$, androsterone and related $\mathrm{C}_{19}$ steroids ${ }^{10)}$, bile acids $^{11)}$ and cholesterol ${ }^{12)}$ have been reported to be dehydrogenated to their 3-ketones.

In the course of studies on microbial metabolism of cardiac glycosides and aglycones in this laboratory, a considerable number of microorganisms tested were found to convert cardiac aglycones into substances which were reactive with 2,4-dinitrophenylhydrazine reagent on paper chromatograms. As the tests for the reactivity of authentic samples of 3dehydrogenated cardiac aglycones with this reagent were positive, dehydrogenation of 3-

\footnotetext{
9) D. Perlman, Science, 115, 529 (1952).

10) P. Talalay and P. J. Marcus, Nature, 173, 1189 (1954); G.E. Turfitt, Biochem. J., 40, 79 (1946).

11) O. Hayaishi, C. Slaughter and W.B. Jakoby, J. Bacteriol., 79,

12) T.C. Stadtman, A. Cherks and C.B. Anfinsen, J. Biol. Chem., 206, 511 (1954); F. J. Loomeijer, Biochim. Biophys. Acta. 29, 168
(1958).
} 


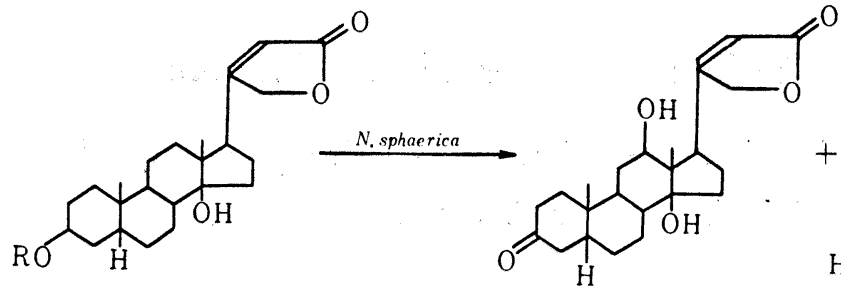

(I) $\mathrm{R}-\mathrm{H}$

(II) $\mathrm{R}=\mathrm{COCH}_{3}$
(II)<smiles>O=C1OCC2=CC1C1CCC3(O)C(O)CCC45CC(O)CCC4C5CCC3C21</smiles>

(IV)

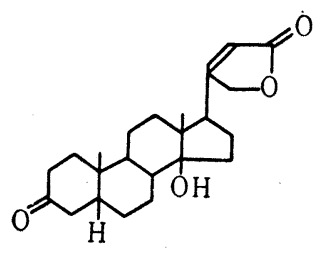

(V)

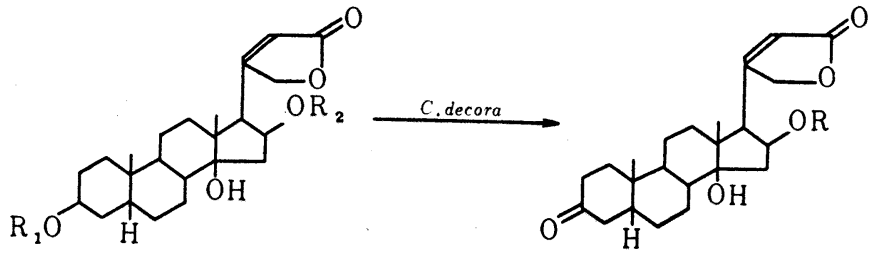

(V) $\mathrm{R}_{1}, \mathrm{R}_{2}-\mathrm{H}$

(II) $\mathrm{R}_{1}=\mathrm{COCH}_{3}, \mathrm{R}_{2}-\mathrm{H}$

(II) $\mathrm{R}_{1}-\mathrm{H}, \mathrm{R}_{2}=\mathrm{COCH}_{3}$

(IX) $\mathrm{R}_{1}, \mathrm{R}_{2}=\mathrm{COCH}_{2}$
(X) $\mathrm{R}-\mathrm{H}$

(XI) $\mathrm{R}=\mathrm{COCH}_{3}$ hydroxyl group to 3-ketone was suspected to occur by microbial activity.

Thus, from the transformation products of digitoxigenin (3 $\beta$,14-dihydroxy-5 $\beta$-card-20(22)enolide) (I) by Nigrospora sphaerica (Sacc.) Mason (oder Moniliales, Fungi Imperfecti) *, 3-dehydrodigoxigenin (3-dehydro-12 $\beta$-hydroxydigitoxigenin) (III) and a small amount of digoxigenin (12 $\beta$-hydroxydigitoxigenin) (IV) were isolated and identified by comparison with authentic samples.

Another microorganism, Calonectria decora (Wallr.) Sacc. (oder Hypocreales, Ascomycetes) seems to have more potent dehydrogenating activity. When incubated with this fungus which has been reported to be a $12 \beta, 15 \alpha$-hydroxylator of progesterone ${ }^{13)}$, digitoxigenin was converted exclusively into 3-

* The mic'organisms belonging to the genus Nigrospora, especially Nigrospora ory «ae, have been reported to hydroxylate progesterone at $11 \alpha$ and $15 \beta$ positions. (R.D. Muir and R.M. Dodson, U.S. Patent, $2,823,170$, Feb. 11, 1958)

13) A: Schubert, G. Langbein and R. Siebert, Chem. Ber., 90, 2576 (1957). dehydrodigoxigenin under the same experimental conditions used as in the case of $N$. sphaerica. Bioconversions of 3-acetyldigitoxigenin (II), 3-dehydrodigitoxigenin (V) and digoxigenin by this microorganism gave the same transformation product, 3-dehydrodigoxigenin, as shown in Table $I$.

The marked dehydrogenating activity of C. decora was exhibited more clearly in the transformations of gitoxigenin (16 $\beta$-hydroxydigitoxigenin) (VI) and its acetyl derivatives. Gitoxigenin was converted into 3-dehydrogitoxigenin (X) without concomittant introduction of hydroxyl group into steroid nucleus. 3-Acetylgitoxigenin (VII) was also transformed into the same compound after enzymatic hydrolysis of acetyl group. Moreover, 16-acetylgitoxigenin (oleandrigenin) (VIII) and 3,16-diacetylgitoxigenin (IX) were found to be dehydrogenated by $C$. decora to 3-dehydro-16-acetylgitoxigenin (XI). In addition to this compound the presence of 
Table I. $R_{F}$ Values of Bioconversion Products of Digitoxigenin and its Derivatives

\section{System}

I

\section{A}

II
0.92
0.99

B

I
C

I II $\quad$ V IV

System I. Toluene-butanol $(3: 1)$-, II. Benzene-ethylene dichloride $(3: 7)$-formamide-acetone $(1: 4)$, ascending method.

A. Authentic samples. B. Aglycones incubated with $N$. sphaerica. C. Aglycones incubated with $C_{p}$ decora.

* These spots gave yellow color with 2,4-dinitrophenylhydrazine reagent.

Table II. $R_{F}$ Values of Bioconversion Products of Gitoxigenin and its Derivatives

System

I

II
A

$\overbrace{\text { IX }}$ XI VII VIII $\mathrm{X} \quad$ VI

$$
0.96
$$

$0.85 *$

0.75

0.67

0.00

0.07 *

$0.25 *$

0.14

0.26

$0.45 *$

0.08

\begin{tabular}{|c|c|c|c|}
\hline VI & VII & VIII & IX \\
\hline & & $0.84 *$ & $\begin{array}{l}0.95 \\
0.85 *\end{array}$ \\
\hline $\begin{array}{l}0.24 * \\
0.08\end{array}$ & $\begin{array}{l}0.25 * \\
0.08\end{array}$ & $\begin{array}{l}0.68 \\
0.25 * \\
0.07\end{array}$ & $\begin{array}{l}0.67 \\
0.24 * \\
0.08\end{array}$ \\
\hline \multirow[t]{2}{*}{$\begin{array}{l}0.00 \\
0.07 *\end{array}$} & $\begin{array}{l}0.00 \\
0.08 *\end{array}$ & $\begin{array}{l}0.00 \\
0.07 * \\
0.15\end{array}$ & $\begin{array}{l}0.00 \\
0.07 * \\
0.15\end{array}$ \\
\hline & 0.25 & $0.47 *$ & $\begin{array}{l}0.47 * \\
0.75\end{array}$ \\
\hline
\end{tabular}

System I. Benzene-ethylene dichloride (7:3)-formamide-acetone (1:4), ascending method. II. Toluene-chloroform (7:3)propylene glycol-methanol $(1: 1)$, descending method.

A. Authentic samples. B. Aglycones incubated with $C$. decora.

* These spots gave yellow color with 2,4-dinitrophenylhydrazine reagent.

gitoxigenin, 3-dehydrogitoxigenin, 16-acetylgitoxigenin and the starting material, 3,16diacetylgitoxigenin was demonstrated by paper chromatographic analysis of bioconversion products of 3,16-diacetylgitoxigenin (Table II) .

N. sphaerica exhibited the same transformation pattern towards gitoxigenin and its acetyl derivatives, although the amounts of 3-dehydrogenated compounds formed were always less than those observed in transformations with C. decora.

\section{EXPERIMENTAL*}

Paper Chromatography. For the paper chromato-

* All melting points are uncorrected; cardiac aglycones of Digitalis used as starting materials in this work were prepared and generously donated to the author by Mr. H. Ishii and Mr. T. Okumura of this Labor atory. graphic analyses of bioconversion products of cardiac steroids, the following solvent systems were used: i) toluene-butanol (3:1) -formamide-acetone $(1: 4)^{14)}$, ii) benzene-ethylene dichloride $(7: 3)$ or $(3: 7)$-formamide-acetone $(1: 4)^{14)}$, iii) toluene-chloroform (7 : 3) -propylene glycol-methanol $(1: 1)^{15)}$. The steroids were developed on Tôyô filter paper No. 51 at $26^{\circ} \mathbf{C}$ and were located using i) alkaline $m$-dinitrobenzene ${ }^{16)}$, ii) trichloroacetic acid in chloroform ${ }^{16)}$, iii) antimony trichloride in nitrobenzene ${ }^{17)}$ or iv) 2,4-dinitrophenylhydrazine ${ }^{18)}$.

Transformation of Digitoxigenin by Nigrospora sphaerica.Nigrospora sphaerica (Sacc.) Mason (culture collection of Nagao Institute, Tokyo) was grown

\footnotetext{
14) O. Schindler and T. Reichstem, Helv. Chim. Acta, 34, 108 (1951).

15) D.R. Colingsworth, et al., J. Biol. Chem., 203, 807 (1953).

16) E. Heftmann and A.L. Hayden, J. Biol. Chem., 197, 47 (19.52).

17) H. Rosenkranz, Arch. Biochem. Biophys., 44, 1 (1953).

18) L.R. Axelrod, J. Biol. Chem., 205, 173 (1953).
} 
in cotton-plugged $500 \mathrm{ml}$ shake flasks containing $100 \mathrm{ml}$ of medium. The medium used in this experiment contained $35 \mathrm{~g}$ of glucose, $20 \mathrm{~g}$ of peptone, $5 \mathrm{~g}$ of corn steep liquor and 11 of distilled water. After inoculation the flasks were incubated at $26^{\circ} \mathrm{C}$ on a reciprocal shaker (140 r.p.m.; $7 \mathrm{~cm}$ amplitude) for 4 days and $20 \mathrm{mg}$ of digitoxigenin in $1 \mathrm{ml}$ of ethanol was charged to each flask. After 10 days' reincubation, the contents of 10 flasks were pooled ( $\mathrm{pH}$ 7.6) and acidified to pH 3.2 with $10 \%$ HCl solution. The mycelium was filtered and extracted with acetone and chloroform successively. The filtrates of fermentation broths were extracted three times using 1 l of chloroform each time. The chloroform extracts were washed with water, dried with anhydrous sodium sulfate, and evaporated to dryness under reduced pressure. Paper chromatographic analysis indicated the disappearance of the starting material and the presence of two transformation products, one of which gave a yellow spot with 2,4-dinitrophenylhydrazine (Table I).

The residual solids thus obtained (704 mg) were dissolved in benzene-chloroform $(9: 1)$ and chromatographed over $21 \mathrm{~g}$ of alumina. The column was eluted by successive elution with benzene, chloroform, and methanol using $30 \mathrm{ml}$ portions of each eluant. The solids obtained from chloroform-methanol (100: 1) eluate were recrystallized from acetone-ether, yielding $25 \mathrm{mg}$ of plates melting at $254 \sim 256^{\circ} \mathrm{C}$. The admixture of this crystal with an authentic sample of 3-dehydrodigoxigenin ${ }^{7,19)}$, did not depress the m.p. Anal. Found: C, 70.79; H, 8.40. Calcd. for $\mathrm{C}_{23} \mathrm{H}_{32} \mathrm{O}_{5}$ : C, 71.10; H, 8.30. $\lambda_{\max }^{\mathrm{EtOH}} 220 \mathrm{~m} \mu(\log \varepsilon 4.17), 275 \mathrm{~m} \mu$ $\left(\log \varepsilon\right.$ 2.00). $\quad \lambda_{\max }^{\text {Nujol }} 5.64,5.74,5.91,6.13 \mu$.

From chloroform-methanol $(50: 1)$ eluates was obtained a small amount of crystals melting at 197 $208^{\circ} \mathrm{C}$, which did not show depression of mixed m.p. with an authentic sample of digoxigeni1 2,20).

3-Dehydrodigoxigenin from Digitoxigenin by Calonectria decora. $200 \mathrm{mg}$ of digitoxigenin were added to the 6-days' culture of $C$. decora (culture collection of Centraalbureau voor Schimmelcultures, Baarn, Holland) grown in Czapek-Dox solution supplemented with $0.5 \%$ corn steep liquor. After shaking for 10 days at $26^{\circ} \mathrm{C}$, the broths $(\mathrm{pH} 8.4)$ were extracted as mentioned above. Evaporation of the solvent gave

19) A. Yamada, Chem. Pharm. Bull., 8, 18 (1960).

20) S. Pataki, K. Meyer and T. Reichstein, Helv. Chim. Acta, 36, 1295 (1953).
$233 \mathrm{mg}$ of residual solids which were chromatographed over alumina. The solids from chloroform-methanol (100:1) eluate were recrystallized from ethyl acetate, yiclding $32.3 \mathrm{mg}$ of crystals, m.p. $234 \sim 246^{\circ} \mathrm{C}$. $\mathrm{Re}-$ crystallization from acetone-ether gave $20 \mathrm{mg}$ of plates: melting at $242 \sim 253^{\circ} \mathrm{C}$. Mixed fusion with an authentic sample of 3-dehydrodigoxigenin did not show m.p. depression.

Paper chromatographic analysis showed the presence of a very small amount of digoxigenin in the fractions eluted with chloroform-methanol $(50: 1)$.

Bioconversion of Gitoxigenin and 3-Acetylgitoxigenin by C. decora. $180 \mathrm{mg}$ of gitoxigenin were incubated for 10 days with 5 days' culture of $C$. decora $(20 \mathrm{mg}$ of gitoxigenin per $100 \mathrm{ml}$ of medium). Papergram analysis of the broths showed the presence of the residual starting material and of the less polar bioconversion product reactive with 2,4-dinitrophenylhydrazine as shown in Table II. The solids obtained by chloroform extraction were chromatographed over $6 \mathrm{~g}$ of alumina. Chloroform-methanol (50:1) eluates. gave after evaporation of the solvent $31 \mathrm{mg}$ of crystals. Recrystallization from acetone-ether afforded $18 \mathrm{mg}$ of prisms, m.p. $201 \sim 209^{\circ} \mathrm{C}$. Admixture with an authentic sample of 3-dehydrogitoxigenin ${ }^{2,19)}$ prepared from gitoxigenin by $\mathrm{N}$-bromosuccinimide oxidation (m.p. $202 \sim 207^{\circ} \mathrm{C}$ ) did not show depression of the m.p. Anal. Found: C, 71.17; $\mathrm{H}, 8.38$. Calcd. for $\mathrm{C}_{23} \mathrm{H}_{32} \mathrm{O}_{5}$ : C, 71.10; H, 8.30.

The acetylation of mother liquor with pyridine and acetic anhydride gave $3 \mathrm{mg}$ of plates, m.p. $242 \sim 247^{\circ} \mathrm{C}$, which showed no depression on admixture with an authentic sample of 3-dehydro-16-acetylgitoxigenin ${ }^{21)}$.

Biooxidation of $200 \mathrm{mg}$ of 3-acetylgitoxigenin in a similar way to the process described above gave $240 \mathrm{mg}$ of steroidal extracts. By chromatographic separation were obtained $29 \mathrm{mg}$ of crystals melting at $190 \sim 203^{\circ} \mathrm{C}$ which yielded, after recrystallization from acetoneether, $16 \mathrm{mg}$ of prisms, m.p. $195 \sim 198^{\circ} \mathrm{C}$. Mixed fusion with an authentic sample did not show depression of the m.p. Anal. Found: C, 70.73; $\mathrm{H}, 8.35$. Calcd. for $\mathrm{C}_{23} \mathrm{H}_{32} \mathrm{O}_{5}: \mathrm{C}, 71.10 ; \mathrm{H}, 8.30 \lambda_{\max }^{\text {nujiol }} 5.61,5.78,5.83,613 \mu$.

3-Dehydro-16-acetylgitoxigenin from 16-Acetylgitoxigenen by C.decora. Incubation of $300 \mathrm{mg}$ of 16-acetylgitoxigenin with $C$. decora gave $305 \mathrm{mg}$ of residual solids, which were dissolved in $3 \mathrm{ml}$ of benzene and

21) A. Hunger and T. Reichstein, Helv. Chim. Acta, 33, 76 (1950); Ch. Tamm and A. Gubler, Helv. Chim. Acta, 41,1762 (1958). 
chromatographed over $6 \mathrm{~g}$ of alumina. Fractions eluted with benzene-chloroform $(2: 1)$ and $(1: 1)$ gave, after evaporation of the solvent, $31 \mathrm{mg}$ of crystals which were recrystallized twice from acetone-ether yielding $6 \mathrm{mg}$ of plates, m.p. $242 \sim 249^{\circ} \mathrm{C}$. Admixture with an authentic sample of 3-dehydro-16-acetylgitoxigenin did not show m.p. depression. Anal. Found: C, 69.43; $\mathrm{H}, 7.93$. Calcd. for $\mathrm{C}_{25} \mathrm{H}_{34} \mathrm{O}_{8}: \mathrm{C}, 69.74 ; \mathrm{H}$, 7.96 .

Acknowledgement The author wishes to ex- press his sincere thanks and appreciation to Prof. S. Tanaka, University of Kyoto, Dr. E. Masuo and Dr. D. Satoh of this Laboratory for their guidance and encouragement throughout this work. $\mathrm{He}$ is also indebted deeply to Messrs. H. Ishii and T. Wada for their kind donation of authentic samples of cardiac aglycones and to Mr. T. Okumura for his cooperation in carrying out the experiments. 